mercially, and many experimenters have taken advantage of this to study its role in caste determination. K. Wanyoni and M. Lüscher (University of Berne, and ICIPE, Nairobi) found that $\mathrm{JH}$ analogues can prevent the formation of reproductives in orphaned colonies of the termite Zootermopsis. With his colleague D. Meyer, Lüscher found $\mathrm{JH}$ activity in the anal secretion of the queen of the mound-building termite, Macrotermes subhyalinus. This work gives a further pointer to the involvement of $\mathrm{JH}$ in termite caste regulation. I. Hrdý (Czechoslovak Academy of Sciences, Prague) induced mortality and abnormally high soldier production on treating termites with $\mathrm{JH}$ analogues. The application of these substances to honeybee colonies resulted in death of some of the brood and sometimes of the queens. There is thus a possibility that some $\mathrm{JH}$ analogues could be used in insect control if their action against honeybees can be restricted.

Although few contributions were concerned with taxonomy, some of the behavioural and ultrastructural investigations that were reported shed light on phylogenetic relationships. H. Markl (Technische Hochschule, Darmstadt) surveyed the occurrence of stridulatory organs in ants and related this to their nesting ecology. Stridulatory organs are found in ground-nesting species and are usually lost when species become surface-nesting or arboreal. R. Koltermann (University of Frankfurt) compared the ability of the Indian honeybee, Apis cerana, and three races of Apis mellifica to learn an association between food and scent. There were marked differences between the two species and among the three subspecies in their ability to 'remember' different scents, for example, the Indian bee remembered orange oil, relative to other scents, better than the Egyptian honeybee, and the Egyptian bee remembered orange scent better than did the Italian bee. This variation in associative learning ability correlates with the distribution of the orange tree, which originated in Asia and spread to the Mediterranean area in the sixteenth century, but is not found in central Europe.

Copies of the proceedings of the congress (seventy published papers) can be obtained from Dr P. E. Howse, Biology Department, University of Southampton ( $£ 3.25$, post free). An important development for the future of IUSSI was a revision of the constitution made at the congress providing for a permanent secretary-general (Dr Howse) whose main duty will be to collect and distribute information among those working on social insects. This should facilitate international cooperation among entomologists and also help to avoid duplication, especially where work in the tropics is concerned.
RADIATION Sufe Doses

from a Correspondent

THE current preoccupation of the people of the United States with consumer pressure groups would have been an important topic at the Third International Congress of the International Radiation Protection Association even if it had not been held in Washington DC on September 9-14. The public reaction in the United States to the application of nuclear energy for electric power production and the associated cost of protecting the environment is of widespread interest, especially when contrasted with the demand for the reduction in the population dose from the use of $\mathrm{X}$ rays for medical diagnosis. G. H. Whipple (University of Michigan) debated the intention of the International Commission on Radiological Protection in recommending that radiation doses should be kept "as low as practicable". He accepted this as a qualitative admonition to prudent judgment and discussed the US Atomic Energy Commission's recent adoption of this as a regulatory standard with numerical limits. He claimed that the AEC philosophy demanded "if it can be done then it must be done" and was without regard for economic and social cost. It was suggested that the application of this philosophy could increase the radiation exposure of reactor operational staff. R. Lapp (consultant, USA) further alleged that the greatest benefit to the public of the United States would come from tackling medical diagnostic $\mathrm{X}$-ray exposure and this was where public expenditure was really required.

B. Lindell (Swedish National Institute for Radiation Protection, Stockholm) offered a simple approach to the allocation of public funds based on the thesis that the dollar equivalent of $1 \mathrm{rad}$ dose to 1 man was $\$ 100$. The investment of $\$ 60$ to reduce the dose to a female from a urography $X$-radiation examination would be justified if it saved 0.6 rad dose. He suggested that it would be appropriate to invest vast sums to reduce avoidable exposure to the whole world population even if this came from natural radiation. The estimated radiation cost of the nuclear power programme was modest, especially when compared with the world population dose from atomic bomb testing.

An estimate of worldwide doses from carbon-14 produced by nuclear reactors was given by V. P. Rublevskiy (Biophysics Institute of the USSR Health Ministry). His prediction of a ten-fold increase in carbon-14 concentrations in the biosphere by the year 2010 implies that some control on these releases may be necessary.

This congress was a timely opportunity for a presentation on the Report of the Advisory Committee on Biological Effects of Ionising Radiations (National Academy of Sciences, Washington, 1972) led by C. L. Colmar (Cornell University). This report was written to provide the United States with a basis for standard setting and gives numerical estimates of the risks from ionising radiation exposure. The authors chose to base their calculations on the assumption that the whole of the US population would eventually receive

\title{
Spacing of Histones on Chromatin
}

IN Nature New Biology next Wednesday (October 17) Bustin presents a fresh approach to the study of the arrangement of histones on chromatin. Isolated, fractionated, histones are antigenic, but their specific antibodies do not react with chromatin. What Bustin has discovered, and put to good use, is that isolated, fractionated, histones when bound, individually, to RNA will elicit antibodies. which will react specifically with the appropriate histones within the native complex.

From this interesting observation, Bustin concludes that the antigenic determinants in free histones differ from those of complexed histones. This is not surprising in that previous physicochemical studies on the isolated histone fractions have shown them to be conformationally very different (more open) in comparison with the same histones in situ. That Bustin attempted the approach described in his forthcoming communication does not seem to have been suggested to him by findings al- ready in the literature, which attests to its originality.

Several fascinating conclusions have emerged from the study of the interaction of one or more of the histone (RNA)-specific antibodies with the corresponding native chromatin: (1) In native chromatin the antigenic determinants of $F_{1}$ and $F_{2} b$ are more available to interact with homologous antibody than those in $F_{3}$ and $F_{2} a_{1}$ and the determinants of $F_{2} a_{2}$ are least available. Bustin suggests that the availability of the various determinants is probably dependent on steric factors (for example, burial of histones inside the complex) and/or conformational changes that occur in the histones on interaction with DNA and other chromosomal proteins. (2) Serial binding of up to four different specific antibodies results in incremental binding. This result suggests that the various histones are spatially separated enough so that their determinants do not overlap. Further ramifications of Bustin's new approach are on their way. 